\title{
Ancient DNA Unveils Important Missing Piece of Human History New Ancient Genomic Research Reveals Information about Human history in China
}

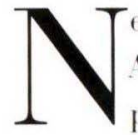

wly released genomes from Neolithic East Isia have unveiled a missing piece of human prehistory. In a new study in Science, a research team led by $\mathrm{FU}$ Qiaomei, a professor at the Molecular Paleontology Lab at the Chinese Academy of Sciences Institute of Vertebrate Paleontology and Paleoanthropology (IVPP), used advanced ancient DNA capture techniques to retrieve ancient DNA from twenty-five individuals dating back to 9.500-+.200 years ago and one individual dating back to 300 years ago from northern and southern East Asia. They reveal the profound role population movement has played in the early genetic history of East Asians.

The newly-sequenced DNA casts a spotlight on an important period in East Asia's early history:

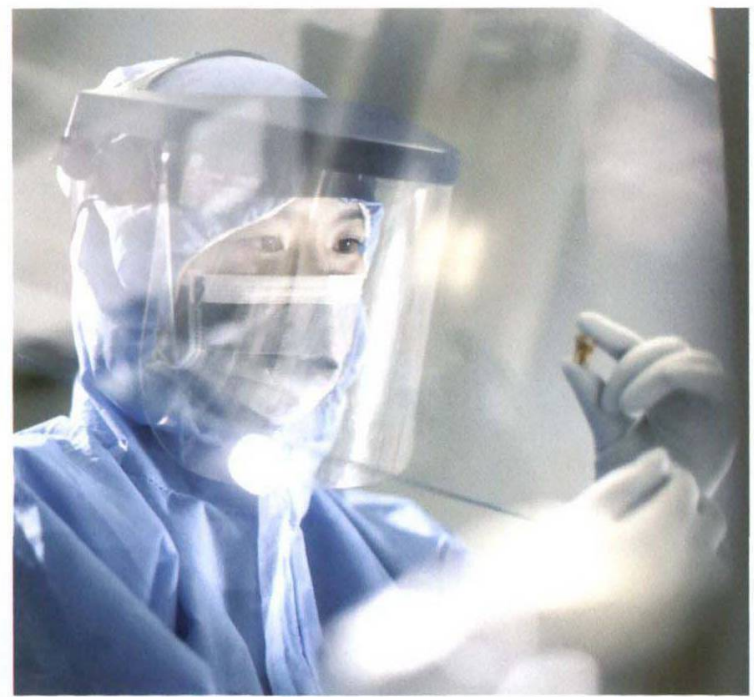

Sampling a tooth in the IVPP cleanroom the transition from hunter-gathering to agricultural economies. One hypothesis for population movement in East Asia is that during the Neolithic, a "second laver" of agriculturalists replaced a "first laver" of huntergatherers in East and Southeast Asia (Matsumura et al., 2018). While the genetics of ancient humans in Southeast Asia, Siberia, and the Japanese archipelago have been well-studied (McColl et al., 2018; Lipson et al., 2018). little is known to date on the genetics of ancient humans in northern and southern China - regions where millet and rice were domesticated. respectively.

FU and her team found that these Neolithic humans share the closest genetic relationship to presentday East Asians who belong to this "second layer", which suggests that by 9.500 years ago, the primary ancestries composing the genetic makeup of East Asians today could already be found in mainland East Asia. While more diverged ancestries can be found in Southeast Asia and the Japanese archipelago, in mainland China Neolithic populations already show genetic features belonging to present-day East Asians. Notably, this includes Early Neolithic southern East Asians who date to $\sim 8.000$ years from this study (Qihe. Liangdao) who were suggested to be "first layer" early Asians like Hòainhians from Southeast Asia (Matsumura et al.. 2018: McColl et al.. 2018). but who Dr. FL and her team instead show share a closer relationship to present-day "second layer" East Asians. Thus, the results fail to support a "two layer" dispersal model in Neolithic East Asia in this area.

One key result is that Early Neolithic East Asians 


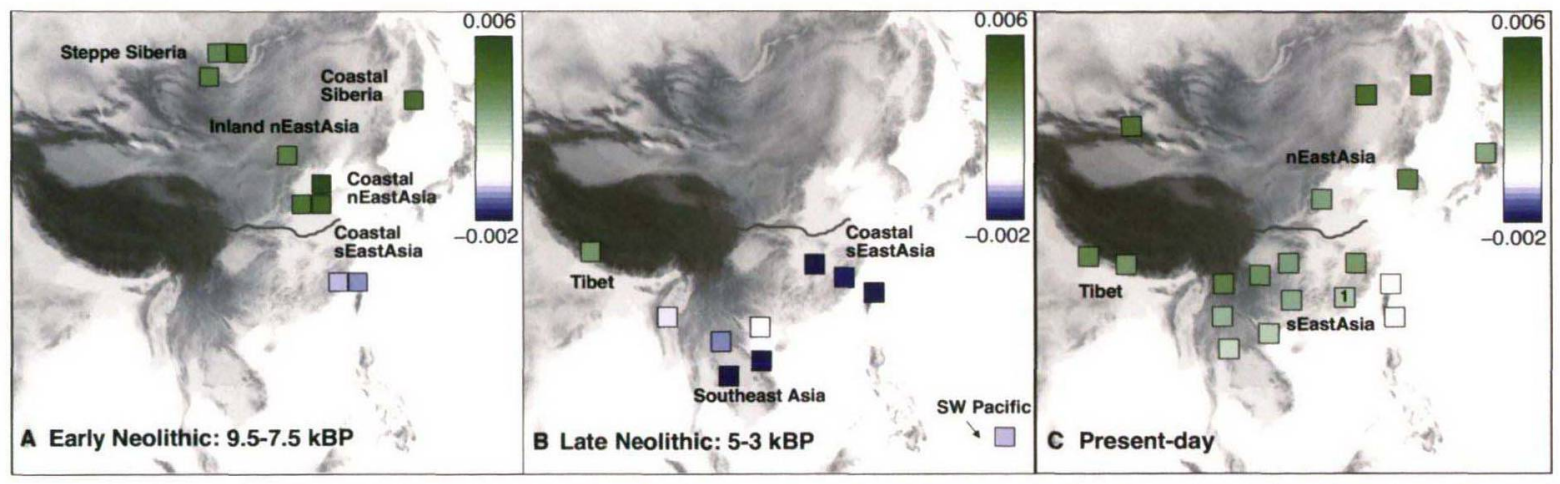

One of the key analyses in the study shows the changes in northern and southern East Asian ancestry over time. In the Neolithic (A-B), northern (green) and southern (blue) ancestry correspond to geography. By the present-day (C), almost all East Asians show more northern East Asian-related ancestry, suggesting population movement from north to south in East Asian prehistory.

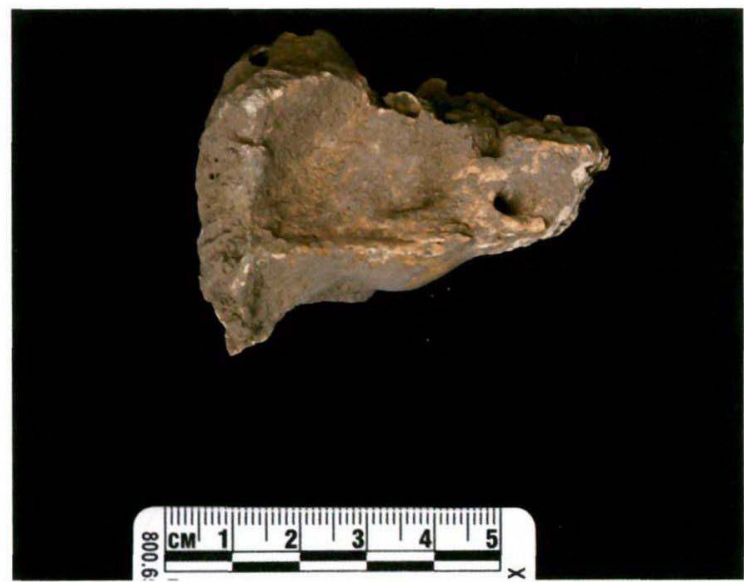

Piece of petrous bone from a $\sim 9,500$-year-old individual from Bianbian Cave, Shandong, China. This individual represents a northern ancestry found along the Yellow River and up into the eastern steppes of Siberia. (Credit: GAO Wei, IVPP)

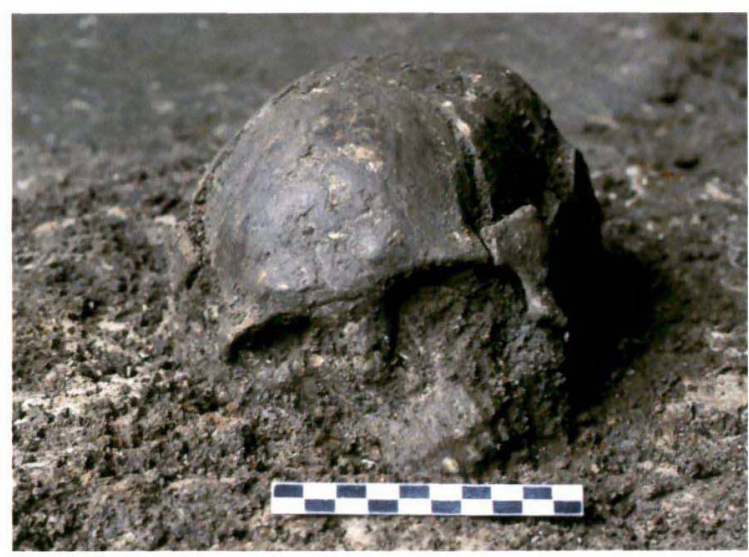

Skull of Qine 2, a 8,400-year-old individual from Qihe cave, Fujian China. This individual's southern ancestry can be found along the coast of mainland southern China and islands in the Taiwan Straits Comparisons to ancient individuals like Qihe 2 show that the deep roots of Austronesian-speakers originated from Neolithic populations from southern China. (Credit: FAN Xuechun, International Research Center for Austronesian Archaeology, Pingtan) are more genetically differentiated from each other than present-day East Asians are. In early Neolithic East Asia since 9.500 BP, a northern ancestry can be found along the Yellow River and up into the eastern steppes of Siberia, distinct from a southern ancestry that can be found along the coast of mainland southern China and islands in the Taiwan Straits since 8,400 BP.

Population movement may have already started impacting East Asians by the Late Neolithic. The Late Neolithic southern East Asians may have shared a connection to the coastal northern East Asian and southern East Asian ancestry also extends north as well.

Today, most East Asian populations do not separate clearly into two distinct groups. Present-day mainland East Asians from both the north and south share a closer genetic relationship to northern Neolithic East Asians along the Yellow River than to southern Neolithic East Asians on the southern coast of China. Further analyses show that they are almost all a mixture of northern and southern ancestry from Neolithic East Asia, with northern ancestry playing a larger role. Population movement, particularly from north along the Yellow River southward was a prominent part of East Asian prehistory after the Neolithic. Interestingly, the presentday Han in all provinces, north and south, show a similar amount of northern and southern influences.

The southern ancestry, while less represented in mainland East Asia today, had extensive influence on other regions. Present-day Austronesian speakers, who share a close genetic relationship to present-day mainland East Asians but live across a wide swath of islands in Southeast Asia and the Southwest Pacific. 
show a remarkably close genetic relationship to Neolithic populations from the southern coast of China. Archaeological materials dating back to the Middle Neolithic have long hinted at the connection between Austronesian islanders and populations in mainland East Asia (Liu \& Chen, 2012), but the genetic relationships uncovered by Dr. FU and her team show unambiguous evidence that Austronesian speakers today originated from a proto-Austronesian population that derived from southern China at least by 8,400 year ago.

The history revealed by these 26 ancient humans highlights the profound impact that population movement and mixture had on human history, but it also indicates a continuity that extends back 9,500 years. Unlike in
Europe (Haak et al., 2015), influences from Central Asia had no role in the formation of East Asian ancestry, with mixing largely occurring regionally between northern and southern populations of East Asia.

The whole slate of ancestries present across East Asia during the Neolithic is still unknown, as genomewide data have not been retrieved from many inland regions of mainland East Asia. But coastal connections between ancient populations in Siberia, Japan. China. and Southeast Asia suggest that as more ancient DNA is retrieved and studied, a complex history of population contact and admixture in East Asian human prehistory will be revealed.

(IVPP)

\section{Note:}

The first author of the work is Dr. Melinda A. Yang, who worked as a postdoctoral scholar at the IVPP under Dr: FU Qiaomei for this project and IS now an assistant professor of biology at the University of Richmond. The corresponding author is Dr: FU Qiaomei. This research was supported in part by grants from the Chinese Academy of Sciences, the National Natural Science Foundation of China, the Tencent Foundation through the XPLORER PRIZE, and the Howard Hughes Medical Institute.

\section{References}

W. Haak et al., Massive migration from the steppe was a source for Indo-European languages in Europe. Nature 522, 207-211 (2015). M. Lipson et al., Ancient genomes document multiple waves of migration in Southeast Asian prehistory. Science 361, 92-95 (2018).

L. Liu, X. Chen, The Archaeology of China: From the Late Paleolithic to the Early Bronze Age. N. Yoffee, Ed., Cambridge World Archaeology (Cambridge University Press, Cambridge, UK, 2012)

H. Matsumura et al., Cranio-morphometric and a DNA corroboration of the Austronesian dispersal model in ancient Island Southeast Asia: Support from Gua Harimau, Indonesia. Plos One 13, (2018).

H. McColl et al., The prehistoric peopling of Southeast Asia. Science 361, 88-92 (2018). 